\title{
Size Effects in Residual Stress Formation during Quenching of Cylinders Made of Hot-Work Tool Steel
}

\author{
Manuel Schemmel, ${ }^{1}$ Petri Prevedel, ${ }^{1}$ Ronald Schöngrundner, \\ Werner Ecker, ${ }^{1}$ and Thomas Antretter ${ }^{2}$ \\ ${ }^{1}$ Materials Center Leoben Forschung GmbH, Roseggerstrasse 12, 8700 Leoben, Austria \\ ${ }^{2}$ Institute of Mechanics, University of Leoben, Franz-Josef-Strasse 18, 8700 Leoben, Austria \\ Correspondence should be addressed to Thomas Antretter; thomas.antretter@unileoben.ac.at
}

Received 5 December 2014; Accepted 16 March 2015

Academic Editor: Wenbin Yi

Copyright (C) 2015 Manuel Schemmel et al. This is an open access article distributed under the Creative Commons Attribution License, which permits unrestricted use, distribution, and reproduction in any medium, provided the original work is properly cited.

The present work investigates the residual stress formation and the evolution of phase fractions during the quenching process of cylindrical specimens of different sizes. The cylinders are made of hot-work tool steel grade X36CrMoV5-1. A phase transformation kinetic model in combination with a thermomechanical model is used to describe the quenching process. Two phase transformations are considered for developing a modelling scheme: the austenite-to-martensite transformation and the austeniteto-bainite transformation. The focus lies on the complex austenite-to-bainite transformation which can be observed at low cooling rates. For an appropriate description of the phase transformation behaviour nucleation and growth of bainite are taken into account. The thermomechanical model contains thermophysical data and flow curves for each phase. Transformation induced plasticity (TRIP) is modelled by considering phase dependent Greenwood-Johnson parameters for martensite and bainite, respectively. The influence of component size on residual stress formation is investigated by the finite element package Abaqus. Finally, for one cylinder size the simulation results are validated by X-ray stress measurements.

\section{Introduction}

Residual stresses are mechanical stresses in solid materials assuming that no external forces are present. The residual stress fields in the surface region of a tool may have a great impact on the lifetime or performance of the tool [1]. They can be beneficial or undesirable depending on the field of application. In most cases, compressive residual stresses near the surface of the tools are favoured. The origin of residual stress can be divided into three categories: mechanical, thermal, and metallurgical [2]. Shot peening or grinding are examples for mechanically induced residual stresses where plastic deformations occur near the surface. Thermally induced stresses play an important role in the field of surface engineering [3] where thin layers with different coefficients of thermal expansion lead to the desired stress fields during the manufacturing process. For these cases, the presence of stresses can be made visible with high spatial resolution by means of X-ray diffraction [4] or by removing the surface layer which will inevitably bend the whole structure [5]. Regarding the heat treatment of steel parts, phase transformations and their accompanying volume changes, also referred to as metallurgical strains, are the main source of residual stresses. There exists a multitude of phase transformation models including classical Avramitype approaches [6] using Scheil's additivity rule [7] up to advanced models which take time dependent cooling into account [8]. Quenching as a vital part of the heat treatment is a very important process in the manufacturing chain of many metallic components. Although the quenching process should be quick enough to generate a supersaturated solid solution, it should be as smooth and slow as possible to 
minimize residual stresses and distortion in the components [9]. High pressure gas quenching has been the preferred process in the heat treatment of hot-work tool steels for many years. The use of gaseous nitrogen instead of liquid oil provides significant benefits during the quenching process. Improvements can be achieved concerning the cleanliness and the homogeneity of the cooling process which leads to a decrease of residual stresses and to a reduction of distortions [10]. The homogeneity of the gas quenching process allows the use of simpler models for the heat transfer compared to oil or water quenching [11]. A wide variety of complex models, primarily computational fluid dynamic models, can be found where the focus lies on the description of the gas flow from the nozzles $[12,13]$. The residual stress distribution is often very complex and may vary from point to point on the surface of complex parts. In case of gas quenching of steels, there are two main sources of residual stresses. First, the evolution of the residual stresses is caused by temperature gradients which result in plastic yielding of the weak austenitic phase at high temperatures. Second, the history of phase transformations and their accompanying inelastic strain components also induce residual stresses. Among these inelastic strain components, the contribution due to transformation induced plasticity where plasticity can be found even at loads below the yield strength of the weakest phase has the biggest impact on the formation of residual stresses. The fact that transformation induced plasticity (TRIP) is highly dependent on the local stress state [14], which is in turn dependent on the temperature gradients in the component, gives rise to a strong size dependence of the residual stress state. Furthermore, it is not clear at first sight whether compressive or tensile residual stresses are obtained on the surface. Although cylindrical specimens have frequently been investigated in the field of computational mechanics and residual stress simulations can be found in $[15,16]$, the effect of cylinder size on the residual stress state close to the surface has not been documented so far. Hence, the goal of this work is to study the phase fractions and the formation of residual stresses near the surface of cylindrical bodies of different sizes considering the influence of transformation kinetics and transformation induced plasticity using suitable modelling tools.

\section{Materials and Methods}

2.1. Phase Transformation Kinetics. Heat treatment simulations of steels require a proper description of phase transformation kinetics. In hot-work tool steels, the austenite-tomartensite and the austenite-to-bainite transformations have to be taken into account. For the given alloy composition, the formation of pearlite can be neglected because the pearlitic phase region is shifted to long transformation times, which are not relevant for conventional heat treatment processes. The bainitic phase transformation model according to $[17,18]$ considers homogenous nucleation and growth of upper and lower bainite. The increase of the radius of the nucleus can be described by

$$
\begin{gathered}
\dot{r}=\alpha_{2}\left(\exp \left[\frac{-\left(\theta-\theta^{*}\right)}{B_{u}}\right] \cdot H\left[\theta_{\mathrm{bs}}-\theta\right]\right. \\
\cdot H\left[\theta-\theta^{*}\right]+\exp \left[\frac{-\left(\theta^{*}-\theta\right)}{B_{l}}\right] \\
\left.\cdot H\left[\theta^{*}-\theta\right] \cdot H\left[\theta-\theta_{\mathrm{bf}}\right]\right),
\end{gathered}
$$

where $\theta$ is the thermodynamic temperature and $\theta^{*}$ represents the temperature of the shortest incubation time in the TTT diagram. $B_{u}, B_{l}$, and $\alpha_{2}$ are parameters and the Heaviside functions determine the possible temperature region of bainitic nucleation between bainitic start temperature $\theta_{\mathrm{bs}}$ and finish temperature $\theta_{\mathrm{bf}}$. After reaching a critical radius

$$
r^{*}=\frac{A_{1} \theta_{0}\left(\theta_{0}-\theta\right)^{0.5}}{\left(\theta_{0}-\theta\right) Q^{*}}
$$

with $Q^{*}$ being activation energy, $A_{1}$ being a parameter, and $\theta_{0}$ being equilibrium temperature, the phase transformation of bainite starts. Due to the metastable character of bainite, the equilibrium temperature $\theta_{0}$ is at higher temperatures compared to the bainitic start temperature $\theta_{\mathrm{bs}}$. The evolution of the bainitic phase fraction $z_{b}$ can be modelled by the following differential equation:

$$
\begin{aligned}
\dot{z}_{b}= & A_{5} \exp \left[\frac{\theta^{*}-\theta}{B_{2}}\right] \cdot \exp \left[\frac{-G^{*}}{R \theta}\right] \\
& \cdot\left\langle\frac{r-r^{*}}{r}\right\rangle^{n} \cdot z_{a}^{\gamma} \cdot H\left[\theta_{\mathrm{bs}}-\theta\right] \cdot H\left[\theta-\theta_{\mathrm{bf}}\right] .
\end{aligned}
$$

In (3), $A_{5}, B_{2}, n$, and $\gamma$ are parameters, $R$ is the gas constant, and $z_{a}$ is the amount of austenite in the microstructure. The Gibbs free energy at the critical radius $G^{*}$ can be described by

$$
G^{*}=\frac{A_{3} \theta_{0}^{2}\left(\theta_{0}-\theta\right)^{1.5}}{\left(\left(\theta_{0}-\theta\right) Q^{*}\right)^{2}}
$$

with $A_{3}$ being another parameter. The incomplete reaction of bainite is an essential topic in the field of hot-work tool steels and has to be taken into account especially at low cooling rates where austenite fractions of up to $30 \%$ are stabilized in the quenched microstructure at room temperature. This effect can be explained by carbon enrichment of retained austenite during bainite formation, which decreases the rate of further bainite and martensite formation. The amount of retained austenite in the simulations is controlled by the parameters of the transformation kinetics and for low cooling rates including isothermal transformations an upper limit of bainite formation according to experiments is introduced. Figure 1 compares the formation of bainite at different cooling rates from experiments and simulation. During a cooling 


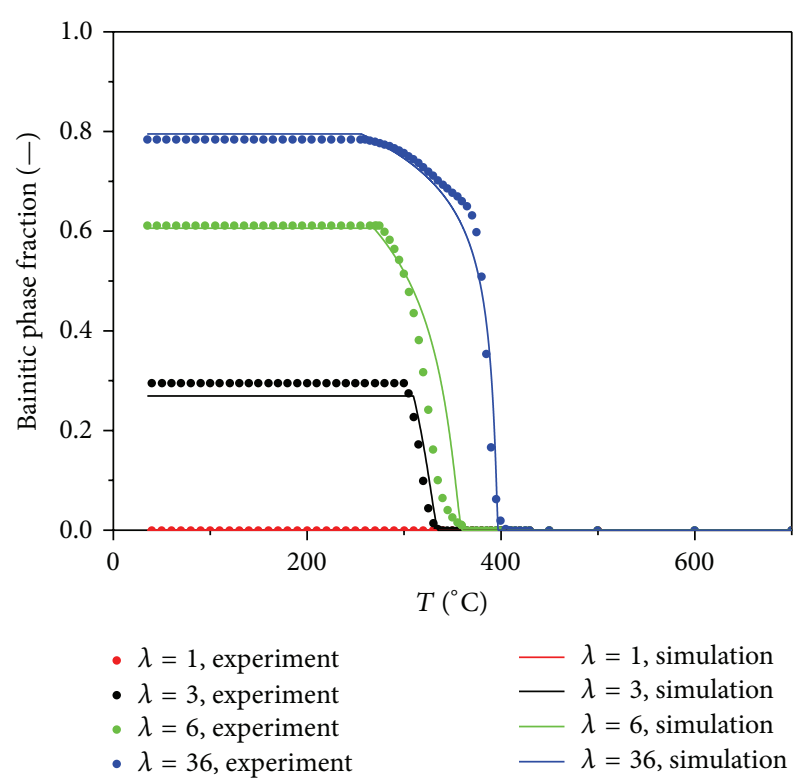

Figure 1: Comparison of calculated and experimental continuous phase diagram of X36CrMoV5-1 hot-work tool steel.

process, the parameter $\lambda$ describes the cooling rate and can be calculated by

$$
\lambda=\frac{t_{500^{\circ} \mathrm{C}}-t_{800^{\circ} \mathrm{C}}}{100} .
$$

The stabilization of retained austenite becomes particularly evident for cooling rates of $\lambda=36$. Here about $20 \%$ of retained austenite is stabilized and will transform neither to bainite nor to martensite during further cooling.

Figure 2 shows the continuous cooling transformation (CCT) diagram of the hot-work tool steel grade X36CrMoV51. The CCT diagram is determined by dilatometric experiments on a "Baehr DIL 805D" quenching dilatometer for a wide variety of cooling rates. All relevant phase regions including austenitic, bainitic, and martensitic phase regions are considered, where the martensite start temperature $M_{S}$ is assumed to be constant at high cooling rates and dependent on the already transformed bainite fraction at lower cooling rates.

The parameters of the phase transformation model are adjusted to the results of continuous dilatometric experiments by a multistage optimization routine [19] and the calculated phase diagram is also plotted in Figure 2. The martensitic transformation rate is modelled by implementation of a Wildau-Hougardy-approach [20].

2.2. Material Properties. In order to perform a thermomechanical heat treatment simulation, it is necessary to ascertain the temperature- and phase-dependent material properties, that is, thermal expansion $\alpha$ th, thermal conductivity $\lambda$, specific heat $c_{p}$, density $\rho$, latent heat $\Delta H$, Young's modulus $E$, and plastic properties such as yield strength $\sigma_{0}$ and strain hardening. Special focus lies on the extraction of flow curves of the pure phases, because the presence of large

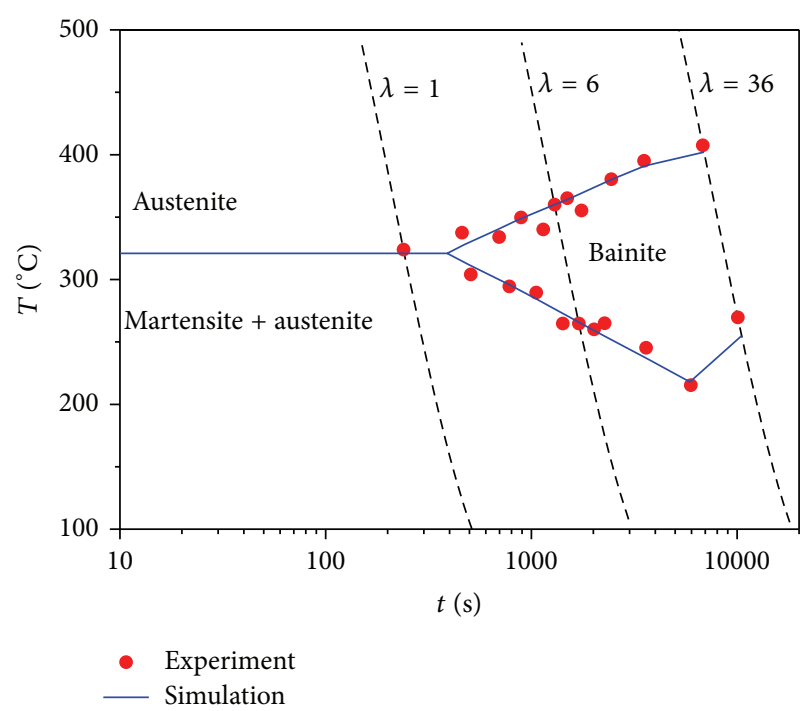

FIGURE 2: CCT diagram of the hot-work tool steel grade $\mathrm{X} 36 \mathrm{CrMoV} 5-1$. The red dots mark the measured data points and the blue lines mark the calculated phase diagram.

amounts of retained austenite in the microstructure prevents getting direct information about the plastic properties of pure martensite or bainite. The yield strength of austenite is much lower compared to the one of bainite or martensite. Compression testing is chosen to measure the flow curves of primarily bainitic and martensitic microstructures using an "Instron 8803" servohydraulic testing machine in the temperature range from $20^{\circ} \mathrm{C}$ to $450^{\circ} \mathrm{C}$. Compression tests offer the advantage of lowering the driving force for stressand strain-induced transformation of retained austenite. The flow curves of austenite were determined on a "Gleeble 3800 " in the temperature range from $450^{\circ} \mathrm{C}$ to an austenitization temperature of $990^{\circ} \mathrm{C}$. Measurements of pure austenitic flow curves at lower temperatures are not possible due to stressinduced transformation of austenite. Therefore, the relative change of the plastic properties of the primarily bainitic microstructure with respect to temperature is also applied to the austenitic flow curves from $450^{\circ} \mathrm{C}$ down to room temperature.

2.3. Transformation Induced Plasticity. Transformation induced plasticity is an especially important consequence of phase transformation. Leblond's law [21] which is valid for a wide variety of materials states

$$
\underline{\dot{\varepsilon}}_{i}^{\mathrm{TP}}=\frac{3}{2} K_{i} f^{\prime}\left(z_{i}\right) \dot{z}_{i} \underline{\mathbf{S}} .
$$

$K_{i}$ is the experimentally determined Greenwood-Johnsonparameter of the $i$ th phase transformation, where $i=1$ represents the austenite-to-bainite transformation and $i=2$ the austenite-to-martensite transformation, respectively. The term

$$
f^{\prime}\left(z_{i}\right)=2\left(1-z_{i}\right)
$$




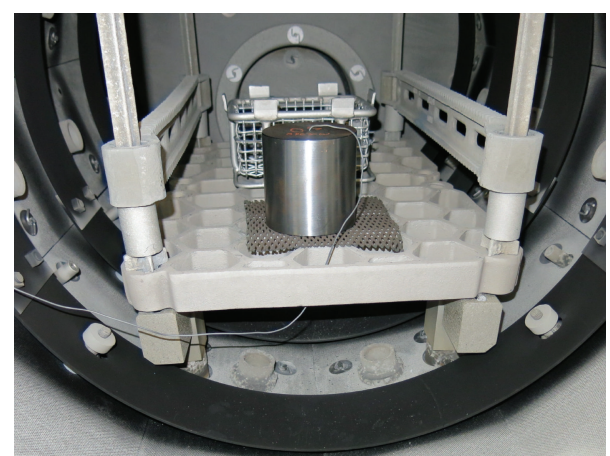

FIGURE 3: Instrumented heat treatment of a cylindrical specimen (diameter and height are $100 \mathrm{~mm}$ ) in a single chamber vacuum furnace. The process parameters are set to austenitizing for $30 \mathrm{~min}$ at $990^{\circ} \mathrm{C}$ and quenching at 6 bar gas pressure.

represents an empirical function that ensures the validity of the TRIP law for a wide range of steel grades. The phase fractions $z_{i}$ and phase fraction rates $\dot{z}_{i}$ in combination with the deviator $\underline{\mathbf{S}}$ determine the TRIP-strain rate $\underline{\boldsymbol{\varepsilon}}_{i}^{\mathrm{TP}}$ of the $i$ th phase transformation. The total TRIP strain is obtained by a linear rule of mixture of the individual strain rates.

2.4. Experimental Heat Treatment. For validation of the simulation results, a cylindrical specimen made of X38CrMoV51 , with a diameter of $100 \mathrm{~mm}$ and a height of $100 \mathrm{~mm}$, is heat-treated in a single chamber vacuum furnace shown in Figure 3. The temperature development is measured by a type $\mathrm{N}$-thermocouple located in the core of the cylinder.

The heating phase includes an intermediate level of constant temperature at $600^{\circ} \mathrm{C}$ for homogenization of the temperature distribution inside the component. After $30 \mathrm{~min}$ of austenitization at $990^{\circ} \mathrm{C}$, the quenching process is initiated using gaseous nitrogen at a pressure of 6 bar. Immediately after reaching room temperature, $\mathrm{X}$-ray stress measurements are performed by a mobile "Xstress 3000 G2" diffractometer on two surface spots down to a depth of $1.5 \mathrm{~mm}$ according to the $\sin ^{2} \psi$ method [22] (see Figure 4 for their locations).

2.5. Model. The simulation of the quenching process starts at an austenitization temperature of $990^{\circ} \mathrm{C}$ followed by a quenching process under conditions modelling the quenching in nitrogen atmosphere. The cooling behaviour of cylinders with the diameter equaling the height is analysed for two different sizes ( $\varnothing 100 \mathrm{~mm}, \varnothing 800 \mathrm{~mm}$ ) in thermomechanically coupled simulations. An axisymmetric model of the upper half of the cylinder using 2D-quadrilateral elements with reduced integration is created. The thermal and displacement boundary conditions are depicted in Figure 5. The heat transfer coefficient (HTC) is regarded as constant on the top and bottom surface and on the lateral surface, respectively. The values of $\mathrm{HTCl}=458 \mathrm{~W} / \mathrm{mm}^{2} \mathrm{~K}$ on the lateral surface and $\mathrm{HTC} 2=485 \mathrm{~W} / \mathrm{mm}^{2} \mathrm{~K}$ on the top surface are determined by inverse optimization and can be considered as moderate compared to cooling rates caused by liquid quenchants [23]. Surface mesh sizes of $250 \mu \mathrm{m}$ and $65 \mu \mathrm{m}$, respectively, are

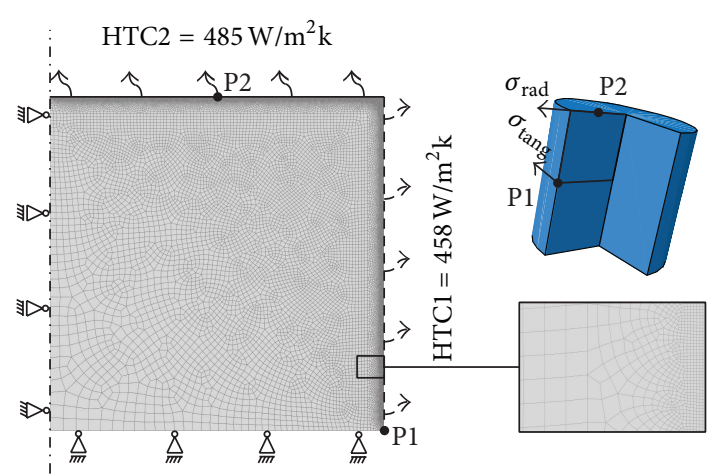

FIgURE 4: Axisymmetric finite element model of a cylinder using quadrilateral elements with reduced integration. Surface mesh sizes of $250 \mu \mathrm{m} / 65 \mu \mathrm{m}$ were used with cylinder diameters of $800 \mathrm{~mm} / 100 \mathrm{~mm}$; the cylinder diameters equal their heights. Two different constant heat transfer coefficients are considered for the lateral (HTC1) and the top surface (HTC2). $\sigma_{\text {tang }}$ is the circumferential stress component in the middle of the lateral surface at position $\mathrm{P} 1$ and $\sigma_{\text {rad }}$ is the radial stress component on the top surface halfway between the centre and the edge at position P2.

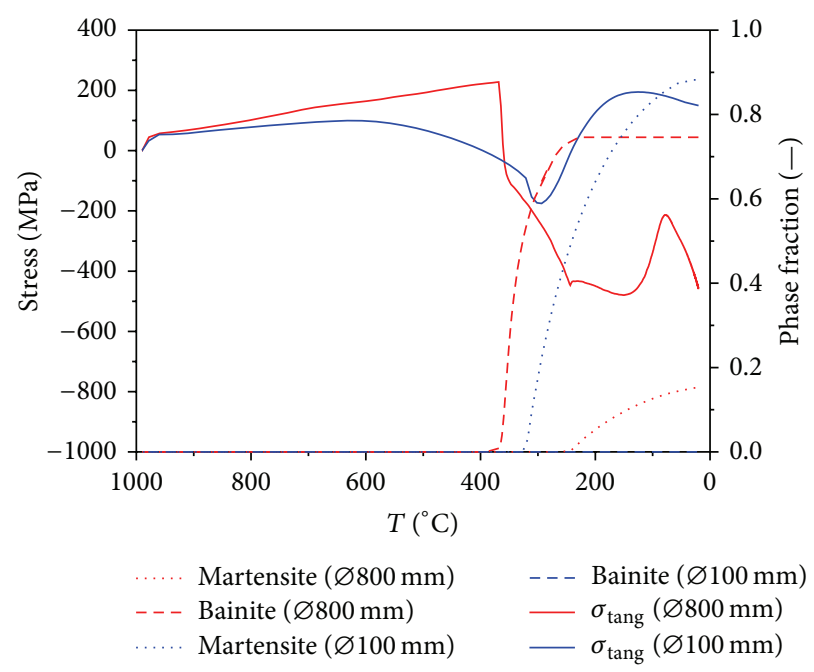

Figure 5: Evolution of tangential surface stresses and phase fractions at position P1 on two cylinders of different sizes $(\varnothing 800 \mathrm{~mm}$, $\varnothing 100 \mathrm{~mm}$ ). The small cylinder is quenched from $990^{\circ} \mathrm{C}$ with gaseous nitrogen at a pressure of 6 bar and the same thermal boundary conditions are applied to the large cylinder.

chosen for the cylinder diameters of $800 \mathrm{~mm}$ and $100 \mathrm{~mm}$ to ensure a good resolution of the temperature gradients. A mesh size influence can be precluded due to the moderate value of the heat transfer coefficient.

\section{Results and Discussion}

3.1. Quenching Simulations. The formation of residual stresses in tangential direction is investigated at half the height of the lateral surfaces (spot P1) of both cylinders in Figure 5. The stress state at this position is approximately 




(a)

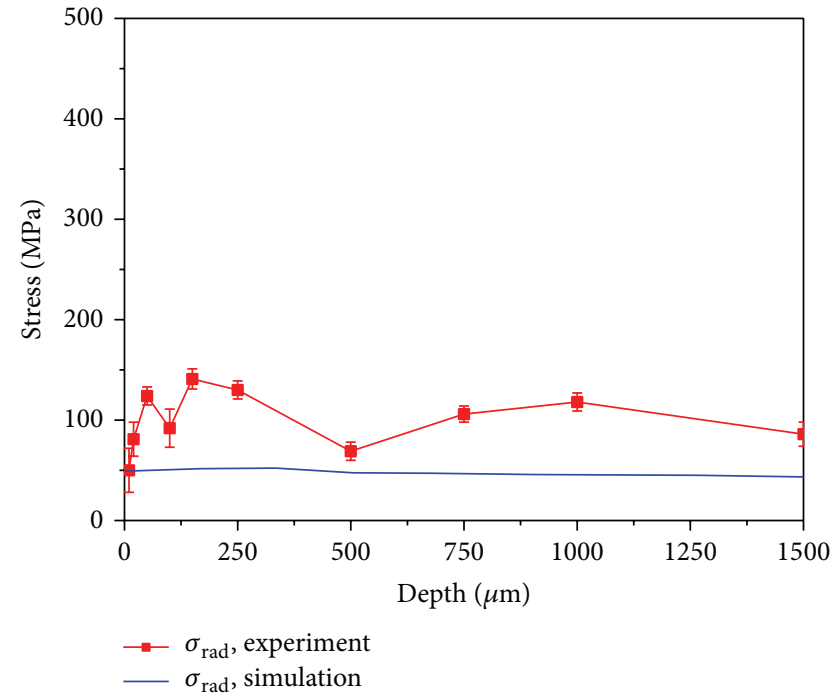

(b)

FIGURE 6: Comparison of simulated and measured (by X-ray diffraction) residual stress depth profiles on a cylinder with a diameter of $100 \mathrm{~mm}$, quenched by 6 bar nitrogen pressure. (a) Tangential stress component on the lateral surface (spot P1). (b) Radial stress component on the top surface (spot P2).

biaxial which means that the absolute value of the investigated stress component is in the range of the equivalent stress.

At high temperatures, both cylinders undergo plastic deformation due to temperature gradients in the tensile regime after a short elastic slope. This can be explained with the low yield strength of austenite at high temperatures. The large cylinder exhibits higher stresses at the surface because of its more pronounced temperature gradients which also leads to a different stress evolution during phase transformations. When the bainitic phase transformation starts in the large cylinder at approximately $400^{\circ} \mathrm{C}$, the small cylinder has already reached the compressive regime whereas the large cylinder remains still in the tensile stress regime. During further cooling, the decrease of the temperature gradients in combination with residual stress due to the plastically elongated material at the surface causes a stress reversal. At the beginning of the martensitic transformation of the small cylinder, the compressive stresses are in the order of $-100 \mathrm{MPa}$. The evolution of phase fraction in combination with TRIP leads to a contraction of the material. As a result, the tangential surface stresses are shifted to lower values in the compressive regime. After the phase transformation in the core of the cylinder, the stresses near the surface are shifted to the tensile regime. After a plateau in the stresses, temperature homogenization leads to a slight decrease of tensile stresses until the final residual stress value of $150 \mathrm{MPa}$ is reached. However, the large cylinder shows an opposite behaviour. During bainitic phase transformation, the initial stress value of $200 \mathrm{MPa}$ in combination with TRIP leads to an elongation of the material which induces compressive stresses during further cooling. Apparently, the stress oscillations are much more pronounced in the large cylinder, especially the last stress peak which can be explained by the longer time delay of the martensitic phase transformation between surface and core regions. Eventually a residual stress value of $-460 \mathrm{MPa}$ can be found on the large cylinder's surface. Both cylinders undergo plastification in the austenitic phase at high temperatures. Due to the fact that the yield strengths of bainite and martensite are higher than $1000 \mathrm{MPa}$, no plastification will occur and the material can then be treated as purely elastic within this temperature range. The only nonlinear contribution comes from TRIP. The resulting residual stresses at room temperature are about $32 \%$ of the yield strength for the large cylinder and about $9 \%$ for the small cylinder. These rather low values can be explained by the high symmetry of the investigated cylindrical geometry. The evolution of phase fractions is also plotted in Figure 5 (dashed lines) and the increase of bainitic phase fraction with decreasing cooling rate is clearly visible. The final phase fractions at the surfaces are $75 \%$ bainite and $15 \%$ martensite for the large cylinder and $0 \%$ bainite and $88 \%$ martensite for the small cylinder. Figure 6 shows the comparison of the calculated residual stress values with the experiments evaluated at the two spots P1 and P2 on the cylinder surface. The error bars in the diagrams indicate the standard deviation according to the linear regression in the $\sin ^{2} \psi$ plots. The effective errors can be increased further by changes of the elastic constants near the sample surface and by a possible anisotropic behaviour (texture) of the material. Furthermore, the nonlinear $\sin ^{2} \psi$ plots indicate a residual stress gradient near the sample surface. At these short distances from the surface, the simulations show almost no changes of the residual stresses with increasing depth. This is apart from the very near surface region in good agreement with the measured residual stress profiles. In the near vicinity of the surface, the measurements show a slight decrease in the residual stresses. These effects can 
be correlated with surface degradation occurring during the heat treatment process. Although the surrounding media are nitrogen atmosphere, oxidation and decarburization occur to some extent but are not considered by the model. Therefore, only long range stresses can be calculated by the model and these stresses are predominantly influenced by phase transformations neglecting any changes of chemical composition. The experimentally determined stress depth profile was measured from $10 \mu \mathrm{m}$ up to $1.5 \mathrm{~mm}$ depth with electrolytic etching performed between the measuring steps. Due to the already mentioned surface phenomena, the value at zero depth is not considered in this discussion. The sign and the order of magnitude of the residual stress components are predicted by the model although the simulated values are only about half the experimental ones.

Surface related effects may come into play that cannot be captured by the model. Furthermore, a nonuniformly distributed heat transfer coefficient may be present and this would also lead to deviations concerning the prediction of residual stresses.

\section{Conclusions}

In this work a multiphase transformation model is introduced which takes into account bainitic and martensitic phase transformations during the quenching process. The material behaviour is modelled by means of phase-dependent thermal and mechanical material properties, transformation induced plasticity, and position-dependent heat transfer coefficients. Heat treatment simulations performed on cylinders with different dimensions show some significant influences on the residual stress formation.

(i) The phase transformation kinetics of a complex hotwork tool steel can be successfully described by the presented modelling scheme.

(ii) The order of magnitude of the tensile residual stresses on the surface of the small cylinder can be predicted by the applied finite element model. A better quantitative agreement requires a closer look at chemical effects in the near surface region and an advanced description of the thermal boundaries.

(iii) In the case of cylindrical geometries increasing size and dimension shifts near surface residual stresses from the tensile regime to the compressive regime.

\section{Conflict of Interests}

The authors declare that there is no conflict of interests regarding the publication of this paper.

\section{Acknowledgments}

Financial support by the Austrian Federal Government (in particular from Bundesministerium für Verkehr, Innovation und Technologie and Bundesministerium für Wirtschaft, Familie und Jugend) represented by Österreichische Forschungsförderungsgesellschaft $\mathrm{mbH}$ and the Styrian and the
Tyrolean Provincial Government, represented by Steirische Wirtschaftsförderungsgesellschaft $\mathrm{mbH}$ and Standortagentur Tirol, within the framework of the COMET Funding Programme is gratefully acknowledged.

\section{References}

[1] R. Ebner, S. Marsoner, I. Siller, and W. Ecker, "Thermal fatigue behaviour of hot-work tool steels: heat check nucleation and growth," International Journal of Microstructure and Materials Properties, vol. 3, no. 2-3, pp. 182-194, 2008.

[2] A. K. Nallathambi, Y. Kaymak, E. Specht, and A. Bertram, "Sensitivity of material properties on distortion and residual stresses during metal quenching processes," Journal of Materials Processing Technology, vol. 210, no. 2, pp. 204-211, 2010.

[3] H. Shang, J. Li, and T. Shao, "Mechanical properties and thermal stability of TiN/Ta multilayer film deposited by ion beam assisted deposition," Advances in Materials Science and Engineering, vol. 2014, Article ID 639461, 8 pages, 2014.

[4] M. Stefenelli, J. Todt, A. Riedl et al., "X-ray analysis of residual stress gradients in TiN coatings by a Laplace space approach and cross-sectional nanodiffraction: a critical comparison," Journal of Applied Crystallography, vol. 46, no. 5, pp. 1378-1385, 2013.

[5] R. Schöngrundner, R. Treml, T. Antretter et al., "Critical assessment of the determination of residual stress profiles in thin films by means of the ion beam layer removal method," Thin Solid Films, vol. 564, pp. 321-330, 2014.

[6] M. Avrami, "Kinetics of phase change. III: granulation, phase change and ,icrostructure," The Journal of Chemical Physics, vol. 9, pp. 177-184, 1941.

[7] C. Verdi and A. Visintin, "A mathematical model of the austenite-pearlite transformation in plain carbon steel based on the Scheil's additivity rule," Acta Metallurgica, vol. 35, no. 11, pp. 2711-2717, 1987.

[8] J. B. Leblond and J. Devaux, "A new kinetic model for anisothermal metallurgical transformations in steels including effect of austenite grain size," Acta Metallurgica, vol. 32, no. 1, pp. 137146, 1984.

[9] S. Eck, P. Prevedel, S. Marsoner, W. Ecker, and M. Illmeier, "Using finite element simulation to optimize the heat treatment of tire protection chains," Journal of Materials Engineering and Performance, vol. 23, no. 4, pp. 1288-1295, 2014.

[10] B. Liscic, H. M. Tensi, L. C. F. Canale, and G. E. Totten, Quenching Theory and Technology, CRC Press, 2nd edition, 2010.

[11] L. Huiping, Z. Guoqun, N. Shanting, and L. Yiguo, "Optimization of technology parameters for the plane-strain component in the process of gas quenching," Applied Mathematical Modelling, vol. 32, no. 5, pp. 860-872, 2008.

[12] N. Lior, "The cooling process in gas quenching," Journal of Materials Processing Technology, vol. 155-156, no. 1-3, pp. 18811888, 2004.

[13] J. Wang, J. Gu, X. Shan, X. Hao, N. Chen, and W. Zhang, "Numerical simulation of high pressure gas quenching of $\mathrm{H} 13$ steel," Journal of Materials Processing Technology, vol. 202, no. 1-3, pp. 188-194, 2008.

[14] F. D. Fischer, G. Reisner, E. Werner, K. Tanaka, G. Cailletaud, and T. Antretter, "New view on transformation induced plasticity (TRIP)," International Journal of Plasticity, vol. 16, no. 7, pp. 723-748, 2000.

[15] W. P. de Oliveira, M. A. Savi, P. M. C. L. Pacheco, and L. F. G. de Souza, "Thermomechanical analysis of steel cylinders 
quenching using a constitutive model with diffusional and nondiffusional phase transformations," Mechanics of Materials, vol. 42, no. 1, pp. 31-43, 2010.

[16] A. Eser, A. Bezold, C. Broeckmann, I. Schruff, and T. Greeb, "Tempering-simulation of a thick-walled workpiece made of X40CrMoV5-1 steel," Journal of Heat Treatment and Materials, vol. 69, no. 3, pp. 127-137, 2014.

[17] R. P. Garrett, S. Xu, J. Lin, and T. A. Dean, "A model for predicting austenite to bainite phase transformation in producing dual phase steels," International Journal of Machine Tools and Manufacture, vol. 44, no. 7-8, pp. 831-837, 2004.

[18] R. Mahnken, A. Schneidt, S. Tschumak, and H. J. Maier, "On the simulation of austenite to bainite phase transformation," Computational Materials Science, vol. 50, no. 6, pp. 1823-1829, 2011.

[19] M. Schemmel, M. Wießner, R. Schöngrundner, W. Ecker, and T. Antretter, "Modellierung von Multiphasenumwandlungen in Warmarbeitsstählen während des Härteprozesses," in Simulationsforum Schweißen und Wärmebehandlung, pp. 11-20, Weimar, 2013.

[20] H. P. Hougardy and M. Wildau, "Berechnung der Wärmebehandlung von Stählen-Umwandlungsverhalten. Spannungen, Verzug," Stahl und Eisen, vol. 105, no. 22, pp. 1289-1296, 1986.

[21] J. B. Leblond, "Mathematical modelling of transformation plasticity in steels II: coupling with strain hardening phenomena," International Journal of Plasticity, vol. 5, no. 6, pp. 573-591, 1989.

[22] U. Welzel, J. Ligot, P. Lamparter, A. C. Vermeulen, and E. J. Mittemeijer, "Stress analysis of polycrystalline thin films and surface regions by X-ray diffraction," Journal of Applied Crystallography, vol. 38, no. 1, pp. 1-29, 2005.

[23] L. Hou, H. Cheng, J. Li, Z. Li, B. Shao, and J. Hou, "Study on the cooling capacity of different quenchant," Procedia Engineering, vol. 31, pp. 515-519, 2012. 

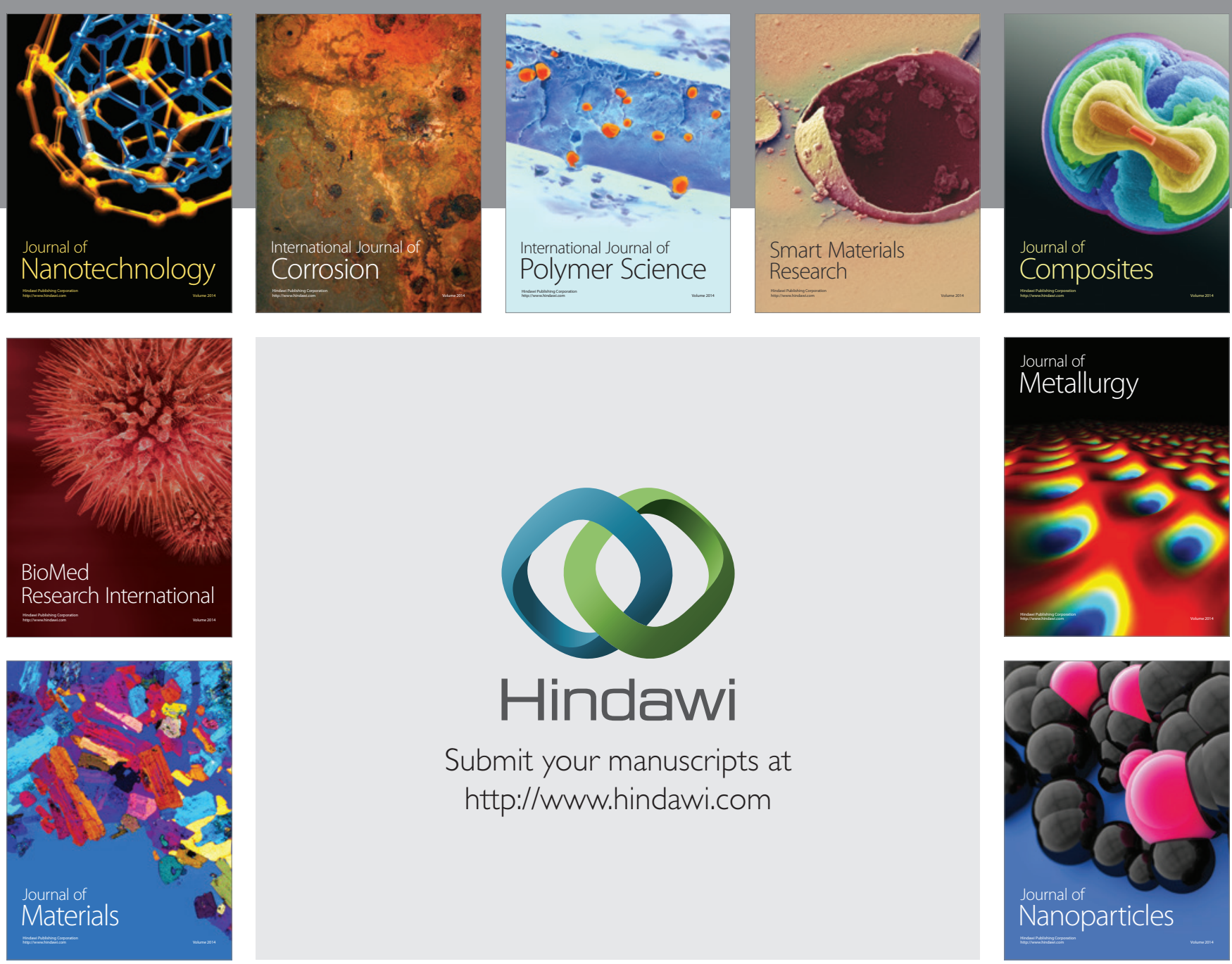

Submit your manuscripts at http://www.hindawi.com
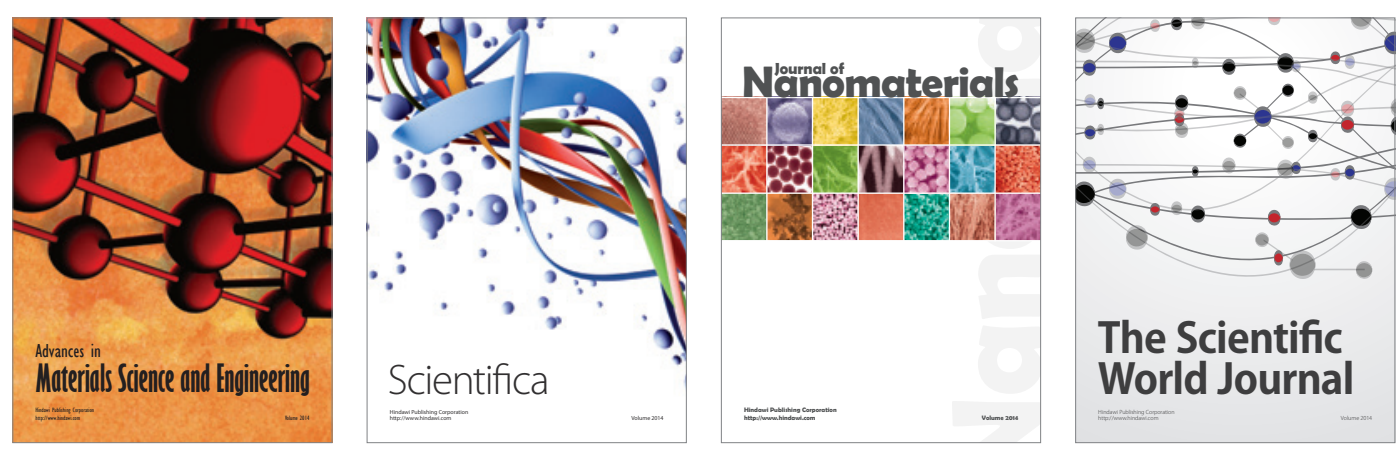

\section{The Scientific World Journal}
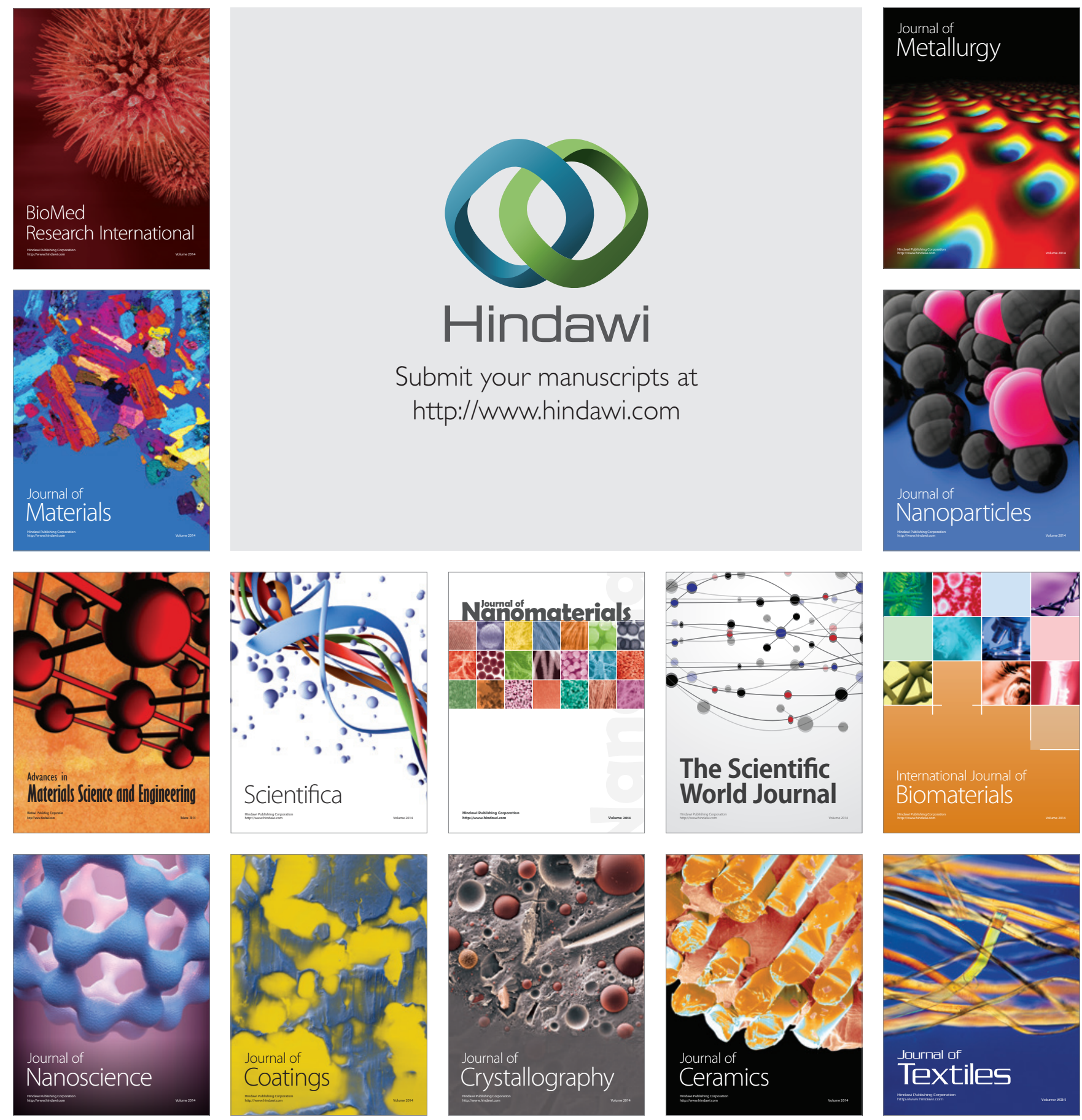